\title{
Does circadian and ultradian glucocorticoid exposure affect the brain?
}

\section{Konstantinos Kalafatakis, Georgina M Russell and Stafford L Lightman}

Laboratories for Integrative Neuroscience and Endocrinology (LINE), Bristol Medical School, Faculty of Health Sciences, University of Bristol, Bristol, United Kingdom

\begin{abstract}
Glucocorticoids are a class of systematically secreted hormones, vital for mammalian life, which are intensively investigated for more than 80 years. They regulate multiple body processes like metabolism, fluid homeostasis, immune and stress system responsivity, as well as brain function. Glucocorticoids have a complex rhythm by which they are released to circulation from the adrenal cortex. The hormone exhibits a circadian variation, with high hormonal levels being secreted just prior and during the active part of the day, and progressively lower and lower amounts being released during the inactive part of it. Underlying this diurnal variation there is a more dynamic, ultradian rhythm composed of frequent episodes of glucocorticoid secretion (hormonal pulses). Accumulating evidence from observational, in silico, in vitro and in vivo, preclinical and clinical studies suggest that both aspects of glucocorticoid rhythmicity are preserved among mammalian species and are important for brain function. The central nervous system is exposed to both aspects of the hormonal rhythm and has developed mechanisms able to perceive them and translate them to differential cellular events, genomic and non-genomic. Thus, glucocorticoid rhythmicity regulates various physiological neural and glial processes, under baseline and stressful conditions, and hormonal dysrhythmicity has been associated with cognitive and behavioural defects. This raises a number of clinical
\end{abstract}

\section{Invited Authors' profile}

Stafford Lightman is Professor of Medicine at the University of Bristol, UK. He started his scientific career working on catecholamines. He then provided some of the first data linking opioid peptides with the regulation of neurohypophysial function and demonstrated the importance of brain stem catecholamine pathways in the regulation of hypothalamic activity. Later he demonstrated the shift from CRH to arginine vasopressin in the control of the hypothalamicpituitary-adrenal axis during chronic stress and characterised the development of stress hyporesponsiveness during lactation in both rats and man. More recently using a combination of mathematical modelling and biological testing he has shown that adrenal stress hormones oscillate and that these oscillations emerge as a natural consequence of the interaction between the pituitary gland and the adrenal cortex. Stafford Lightman is a Fellow of The Royal Society and a founder Fellow of the Academy of Medical Sciences.

Dr Konstantinos G Kalafatakis MD MSc PhD MAPS MRSB is a Medical Doctor (University of Athens) and a Neuroscientist. He is a Neurology Resident in the University Hospital of Heraklion (Crete, Greece), Postdoctoral Research Fellow of the University of Ioannina (Greece) and Honorary Research Fellow of the University of Bristol (UK). Since 2013, he has been studying the role of glucocorticoid rhythmicity in modifying neural network dynamics related to mood regulation, memory and emotional processing. Prior to this, he was conducting neuropharmacological experiments on animal models of neuroendocrine and neurovascular disease

Published by Bioscientifica Ltd.
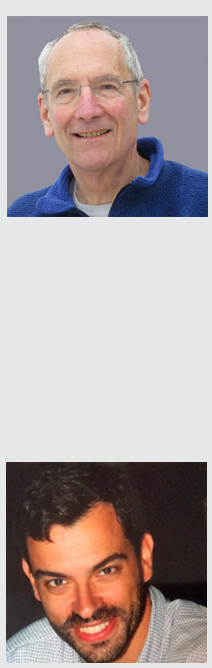
implications concerning (i) glucocorticoid involvement in neuropsychiatric disease and (ii) improving the therapeutic efficacy or expanding the role of glucocorticoid-based treatments in such conditions.

\section{Introduction}

Glucocorticoids (GCs, corticosterone in rodents and predominantly cortisol in human) are a class of steroid hormones, vital for mammalian life, which are synthesised by the adrenal glands, secreted into the systematic circulation and travel throughout the body to exert their pleiotropic effects on cellular function, primarily affecting metabolism, the immune system and cognitive and emotional functions. The complexity of their biology is illustrated by the fact that after almost 80 years of intensively investigating these molecules, we still have only superficial understanding of their molecular effects and the system level homeostatic functions they control.

Despite these caveats, almost all clinical specialties use natural or synthetic GCs to treat multiple conditions, primarily exploiting their immunomodulatory actions on high doses; from gastroenterologists (inflammatory bowel disease), dermatologists (serious allergies, psoriasis), rheumatologists (rheumatoid arthritis, systemic lupus erythematosus and other autoimmune disorders) and pulmonologists (asthma) to surgeons (serious bacterial infections and shock), oncologists (in combination with first-line anti-neoplastic drugs under multi-drug schemes), nephrologists (some forms of glomerulonephritis), anesthesiologists (in combination with first-line pain killers under multi-drug schemes), neurologists (multiple sclerosis, other inflammatory or traumatic encephalopathies, myelopathies and neuropathies) and endocrinologists (mainly for replacement therapy in adrenal insufficiency) $(1,2,3)$.

The need to fully elucidate GCs' biological relevance is crucial since GCs are a fundamental aspect of the nonspecific neuroendocrine response of the mammalian body to multiple internal and external stressors. One of the major systems affected in these states is the central nervous system, and it is well recognised that long-term or high-dose GC therapy is associated with neuropsychiatric disorders.

Two of the most characteristic features of GC physiology, well explained in relevant medical textbooks, are their circadian variation and their central role in stress responses. Indeed, GCs are a paradigm for the role of internal biological clocks, regulating the variations in biological needs across the 24-h day. A few hours before awakening (morning in human and night in rodents), the hypothalamic suprachiasmatic nucleus $(\mathrm{SCN})$ reduces its inhibitory input to the paraventricular nucleus $(\mathrm{PVN})$ and median eminence (4), which in turn allows an increase in the secretion of corticotropin-releasing hormone (CRH) into the hypophyseal portal circulation. Consequently, CRH upregulates corticotrophin (ACTH) secretion by corticotropic cells of the anterior pituitary, which travel via the systemic circulation to adrenal glands and stimulate GC biosynthesis/ release. This results to the natural circadian peak of GCs, followed by a gradual fall to reach nadir levels during the inactive part of the day. The circadian characteristics of GC secretion may vary both within and between individuals. They depend on genetic, epigenetic, age- and gender-related variables $(5,6,7)$, intrinsic environmental factors and long-term neurocognitive adaptations to perceived stress, as well as the integrity of the corresponding anatomical structures involved in the feedforward-feedback circuits (8), and the mode of function of peripheral clocks, regulating for instance the circadian variation of the adrenal sensitivity to ACTH stimulation (9).

Responses to external as well as internal stressful stimuli also elicit a dramatic increase in GC secretion. Both brainstem and limbic structures are important in these responses. The hippocampus for example exerts an inhibitory effect over HPA activity at the onset and termination of the stress response (10), while the amygdala enhances the stress-related GC secretion in a regionspecific manner, with central and medial amygdaloidal nuclei being responsive to different stressful stimuli (intrinsic-inflammatory and extrinsic-environmental respectively) and subsequently contributing to the acute stress responses. On the other hand, the basolateral amygdala has a role in the chronic stress integration. Parts of the prefrontal cortex also regulate HPA activity, and consequently, GC secretion. All these brain structures project via the bed nucleus of stria terminalis to subcortical, hypothalamic and brainstem regions that in turn innervate 
the medial parvocellular part of PVN (11). This implies that, in the context of stress responses, multiple steps are involved in the chain of regulatory control initiated by central stimuli, with the final message though eventually translated into changes in hypothalamic CRH secretion (consequently leading to changes in ACTH secretion and thus changes to GC secretion).

What has been much less clear in textbooks on medical physiology is the fact that under baseline conditions the GC circadian variation is actually made up from an underlying, more dynamic rhythm; oscillatory pulses of ACTH and GCs. This is the ultradian rhythm of the hormone. Where does this ultradian rhythm derive from? And is it biologically significant, especially for brain function? And if yes, are there any clinical implications concerning GC involvement in neuropsychiatric disease or improving the therapeutic efficacy of GC-based treatments or even expanding their role in neuropsychiatric conditions? This review will try to answer some of these questions by providing a summary of the relevant scientific evidence.

\section{Is there an ultradian rhythm? Observational and in silico studies on GC pulsatility}

\section{GC pulsatility is a conserved mechanism in mammalian species}

Surprisingly, despite the fact that GC pulsatility had been observed as early as the 1970s, there has been little or no investigation of its biological importance until the last decade. There are no mammalian species studied which lack GC pulsatility, and this includes rodents, sheep, deer and cows $(12,13)$ as well as horses and monkeys. The baseline frequency of this ultradian rhythm may alter with the size and the developmental stage of the animal, being less than $60 \mathrm{~min}$ for rodents and late-gestation fetal horses (14), more than 60 for rhesus macaques $(15,16)$ and deer (17), and $90 \mathrm{~min}$ in sheep (18). All these studies have also demonstrated the existence of a strong correlation between ACTH and GC ultradian rhythms $(14,16,19)$. In this context, a more recent study on rodents provided strong evidence that ACTH pulsatility is necessary for GC pulsatile biosynthesis and secretion, and indeed the exposure of adrenal glands to non-pulsatile ACTH abolished their capacity to produce a pulsatile transcriptional activity of genes involved in steroidogenesis, leading to a loss of adrenal corticosterone secretion (20). Moreover, the experimental disruption of circadian inputs to the HPA activity (for instance lesioning hypothalamic nuclei or exposing animals to constant light conditions) did not interfere with the ultradian component of GC rhythmicity (21).

Multiple clinical observational studies have also confirmed the presence of the ultradian GC rhythm in man, under healthy conditions $(19,22,23,24,25)$, as well as under pathological conditions related to chronic stress system activation, including neurodegenerative disorders (26), depression (27), fibromyalgia and chronic fatigue syndrome (28) or obstructive sleep apnoea (29). The GC pulses vary in amplitude and duration throughout the day due to variable input from hypothalamic nuclei, and a typical human 24-h profile, under healthy and non-stressful conditions, contains approximately 8-16 glucocorticoid pulses (occurring every 60-180 min) (23, 30). The ultradian rhythm of GC secretion is also preserved across gender (31) and, despite changes in pulse amplitude and duration, even during acute stress responses $(32,33)$. But where does this ultradian rhythm come from?

\section{Origin of GC pulsatility}

Since the ultradian rhythm of GC secretion is not abolished by the removal of hypothalamic CRH circadian cues, we focused on the characteristics of the interplay between the anterior pituitary and adrenal glands. As mentioned earlier, ACTH plays a key role on this: after reaching the steroidogenic cells of the zona fasciculata, it binds to its specific receptor melanocortin type-2 (MC2R), causing an increase in the intracellular levels of cAMP, which in turn activate the protein kinase A pathway, leading to posttranslational modifications (mainly phosphorylation/ activation) of proteins involved in cholesterol metabolism like the hormone-sensitive lipase and the steroidogenic acute regulatory protein, which regulate the levels of intracellular cholesterol and its transport within the mitochondrial matrix to initiate the steroidogenic process (34). Therefore, ACTH exerts a positive feedforward regulation on GC biosynthesis.

After release into the systemic circulation, GCs feedback on corticotropic cells of the anterior pituitary to inhibit the release of ACTH. This results in a negative (self)regulation on GC biosynthesis. This positive feedforward-negative feedback loop is characterised by built-in delays (i.e. there is an inherent temporal distance between each positive feedforward activation of MC2Rs by ACTH and the subsequent release of GCs due to the need for de novo GC biosynthesis). Using mathematical biomodelling approaches, accommodating the previously mentioned dynamics between ACTH and GC secretion 
with the inherent delays, as well as other parameters related to GC clearance through liver (bile acids) and kidneys (urine) (35), we were able to demonstrate that the interplay between pituitary and adrenals creates a system that leads its components (ACTH, GCs) to a selfsustaining oscillatory activity $(21,36,37)$, independent of any other cues. What we have described is in effect a sub-hypothalamic pulse generator (Fig. 1).

This leads us to the key question: as the brain is naturally exposed to these GC pulses, how are brain cells able to perceive GC pulsatility and translate for appropriate signalling events? Furthermore, what are the implications of this for therapeutics - both replacement therapy and synthetic corticosteroid treatment?

\section{The neurobiological significance of the GC circadian rhythm}

Before focusing on the ultradian rhythm of GCs, we should not underestimate the significance of their diurnal variation for brain function. GC circadian rhythmicity is an integral feature of the regulation of glucose homeostasis, impacting directly on neuronal and glial homeostasis (38). The GC circadian rhythm is synchronised with the rhythm of other major, brain-specific stimuli such as brain-derived neurotrophic factor, which has a direct interaction with GCs regulating fundamental neural and circuital processes like neurogenesis, dendritic remodelling and synaptic plasticity (39). The GC surge of the diurnal peak also modulates the rhythmic expression of various GC-sensitive genes in a brain region-specific manner, like tryptophan hydroxylase-2 in the raphe neurons (40) or period-2 in the central nucleus of the amygdala (41) and promotes stimulus-driven, non-genomic events, like the postsynaptic dendritic spine formation in the cortex after motor skill learning. At the same time, GC circadian troughs are required for stabilising newly formed spines crucial for long-term memory retention. Conversely, chronic and excessive exposure to GCs eliminates learning-associated new spines and disrupts previously acquired memories (42).

In addition, the circadian rhythm of GCs has enormous, multi-level effects on behaviour, psychophysiology and pathology: (i) changes in the characteristics of the diurnal variation (steeper peaks or flatter slopes) have been linked to an increased self-reported negative affect (43), and an inverse relationship has been reported between the diurnal rhythms of cortisol and positive affect (44). (ii) The diurnal cortisol profile has also been associated

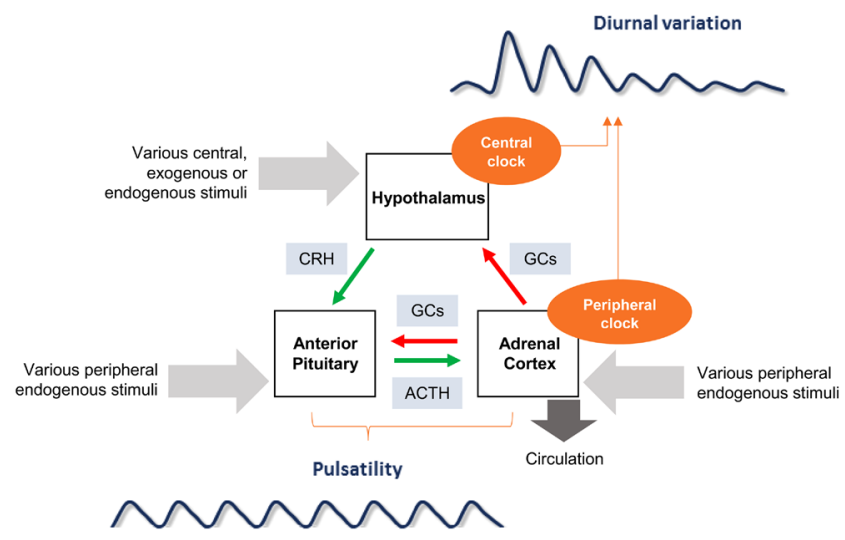

Figure 1

Regulation of glucocorticoid (GC) circadian and ultradian oscillations. In hypothalamus, the suprachiasmatic nucleus regulates the circadian changes in secretion of the corticotropin-releasing hormone (CRH) from the neighbouring paraventricular nucleus. This in turn provides the diurnal pattern of activation of the pituitary corticotropes (green arrow) which secrete corticotropin (ACTH) into the circulation and thence the adrenal cortex where it initiates a feedforward activation of GC biosynthesis (green arrow).This necessity for de novo GC biosynthesis (which cannot be stored in vesicles due to its lipophilic nature) results in a built-in delay before the metabolic product can be released, and feedback at the level of the pituitary to suppress ACTH (red arrow). Mathematical biomodelling suggests that such a positive feedforward-negative feedback system with built-in delays leads to a self-sustaining oscillatory activity and is the basis for ultradian GC pulsatility. Changes in hypothalamic drive can superimpose on this rhythm, by modifying the amplitude and magnitude of each ACTH pulse, and thus establishing the well-recognised diurnal rhythm. This is itself modified by feedback inhibition from the circulating levels of GCs (red arrow). The adrenal cortex itself has a local clock mechanism that also contributes to circadian variation by altering adrenal sensitivity to ACTH stimulation across the circadian cycle. The activity of corticolimbic brain regions (in response to external cues or internal states), brainstem (responding to inflammatory stimuli or pain) as well as other peripheral stimuli (for instance inflammatory cues or stressors) may affect the downstream pathways either controlling the secretion of CRH or the tissues' sensitivity to the ACTH or GC stimulation.

with the neural activity in parts of the medial prefrontal cortex (ventromedial and orbitofrontal), an association that is lost in anhedonic subjects (45). (iii) Enhancement of the diurnal peak of GCs (without changing the overall 
amount of daily GC exposure or any other aspects of the HPA activity) may exert anxiolytic effects (46). (iv) Elimination of the GC circadian peak leads to a significant reduction in locomotor activity during the active periods of the day, comparable to the inactive parts of it (47). (v) Circadian misalignment due to GC circadian rhythm phase shifts has been linked to acute episodes (mania or depression) in the context of bipolar disorder (48). (vi) The diurnal variation in circulating GCs modulates the analgesic effect of morphine by regulating the expression of the $\mu$-opioid receptors in brainstem (49).

It is clear that the GC circadian rhythm provides a strong chronobiological signal controlling the daily homeostasis of energy balance in brain cells, as well as fundamental aspects of neural survivability, plasticity and multi-neuronal network characteristics. These effects are linked to both genomic and non-genomic cellular events, and eventually contribute to the circadian variability of mood and behaviour, whose disruption is linked to psychiatric symptomatology (Fig. 2). Thus, over a period of $24 \mathrm{~h}$, the alternation of the circulating GC levels between a state of high abundance and a state of low bioavailability seems to be crucial for brain physiology. The next question is whether the ultradian pattern of GC rhythm could be of similar neurobiological significance. Is it possible that the circadian variation of the hormone can only be optimally translated into its neurobiological effects if delivered in a pulsatile manner?

\section{Preclinical studies on the neurobiological significance of GC pulsatility}

\section{Does the brain perceive GC circadian and ultradian rhythms?}

The debate around the significance of GC rhythmicity on brain function would be pointless if the nervous system was not exposed to oscillating signals of extracellular GCs. In the systematic circulation, GCs are bound to GC carrier proteins and albumin, and it is only the free fraction of cortisol that is active and available to diffuse into the central nervous system. And even then, this active fraction of GCs can get excreted at the site of the bloodbrain barrier (due to the activity of the P-glycoprotein) and locally, in the microenvironment of neurons and glia, be converted to inactive forms (50). In vivo micro-dialysis studies in rodents have demonstrated, though, that both the circadian and ultradian rhythms of free GCs are maintained in the systemic circulation, the nervous system

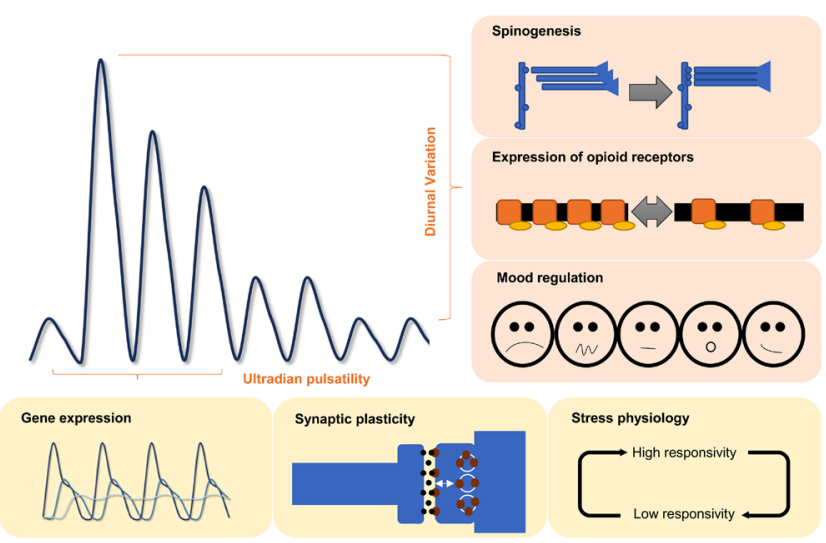

\section{Figure 2}

The complex rhythm of glucocorticoid (GC) synthesis has major neurobiological significance. The GC diurnal peak promotes stimuli-driven, postsynaptic dendritic spine formation in the cerebral cortex, facilitating the learning process. At the same time, GC circadian troughs are required for stabilising these newly formed spines, and thus achieving long-term memory retention. Loss of the diurnal variation in GC levels eliminates learning-associated new spines and disrupts previously acquired memories. Other examples on the significance of the circadian GC rhythm include the time-of-day-dependent analgesic effect of morphine (due to the GC-dependent circadian variability in the expression of $\mu$-opioid receptors in the brainstem) and the association of changes in GC diurnal variation in humans with self-perceived positive and negative affect. Ultradian GC pulsatility also has neurobiological consequences. Each pulse is translated into a GC receptor-DNA-binding event (left bottom yellow frame, dark blue oscillations), subsequently translated into a pulsatile biosynthesis of heterogeneous nuclear RNA (hnRNA, left bottom yellow frame, blue oscillations), which regulates mature transcript of GC-sensitive genes (left bottom yellow frame, light blue curve). Furthermore, the frequency of GC pulses differentially regulates processes crucial for synaptic plasticity, including release of glutamate from presynaptic terminals and glutamate receptor trafficking of postsynaptic neurons. Finally, GC pulsatility enables the rapid alternation between periods with reduced and periods with increased responsivity to stressful insults across the day.

and the subcutaneous tissue (51). These observations are gender independent (52). It is worth noting though, that this synchronicity between plasma and brain free GC oscillations might be modified under conditions of acute changes in the mode of the GC rhythm, as in the context of an acute stress response (53). These results have partially also been confirmed in man (54). 


\section{Is the brain able to translate GC pulsatility into cellular events?}

The debate around the significance of GC pulsatility on brain function would also be pointless if the brain cells did not possess the means to translate dynamic hormonal oscillations into differential signalling events. Neurons and glial cells have developed ways to sense GC pulsatility. The basis of this sensation lies in the properties of the two classes of GC-sensitive receptors, the mineralocorticoid receptors (MRs) and the glucocorticoid receptors (GRs), found in the central nervous system. Since many areas of the brain lack the enzyme 11ß-hydroxysteroid dehydrogenase isoform II, cortisol and corticosterone can activate both GRs and MRs in these areas. The most prominent sites of MR expression in the central nervous system include hippocampus, lateral septum, amygdala and to a lesser extent cerebral cortex, cerebellum, caudateputamen complex and hypothalamus, while areas of GR expression include cingulate cortex, hippocampus, PVN and supraoptic nucleus, lateral geniculate, lateral and medial amygdala, thalamus, cerebellum and cerebral cortex $(55,56,57,58)$.

MRs have a much higher affinity for binding with GCs compared to GRs; consequently, MRs remain occupied even during low GC levels, while GR binding requires higher GC concentrations, like those during the peak of individual pulses or following acute stress (59). Moreover, over the last two decades, it has been gradually realised that these classes of receptors, although considered as transcription factors (i.e. regulators of gene expression) with delayed effects, also possess rapid, non-genomic effects in brain cells; these effects have been attributed to non-nuclear variants of these receptors, and for those effects higher GC levels are required as well. Thus, depending on the GC levels, a different combination of MRs and GRs get activated, resulting in a different set of rapid and delayed effects (60).

The ultradian GC rhythm determines the cyclical shift in the location of GRs and to a lesser extent MRs. At the peak of an endogenous pulse, GRs translocate to the nucleus and bind to glucocorticoid response elements on the DNA, initiating chromatin modifications including histone acetylation and docking of RNA polymerase 2 to initiate gene transcription. At the trough of each pulse, GRs will come off the DNA and either remain in the nucleus bound to chaperone proteins or be ubiquitinated and enter the nuclear proteasome for degradation $(61,62$, 63). Duration of GC exposure also differentially regulates GR and MR expression, as well as determining the binding properties of MR- and GR-related coactivators and corepressors, and the formation of MR-GR heterodimeric complexes $(64,65,66,67,68,69,70)$.

The overall result of this is that corticolimbic regions of the brain - in particular - are equipped with the molecular machinery to sense GC pulsatility; the next question arising therefore is where do all these events lead to? What aspects of neural and brain function are regulated by GC pulsatility?

\section{Which aspects of neural and brain physiology are modulated by GC pulsatility?}

Over the last decade, research efforts exploring the neurobiological significance of GC ultradian rhythmicity have intensified. A variety of neural processes seem to be sensitive to GC pulsatility ranging from genomic events to rapid modifications in synaptic plasticity, hippocampal neurogenesis (71) and, eventually, behavioural phenotypes.

GC-dependent genomic events are sensitive to the dynamic pattern of the hormonal oscillations and form transcriptional patterns that respond differentially to specific aspects of GC rhythmicity in a brain regionspecific manner. The latter has been shown by both, in vivo and in vitro experimentation. For instance, hourly corticosterone pulses in rodents induced episodic bursts of transcription of the gene period-1 in the hippocampus. This led to a plateau in the accumulative mature transcript throughout the time course of the pulsatile exposure, indicating that GC pulsatility works optimally for steady state period-1 expression. The plateau dropped to baseline within $2 \mathrm{~h}$ of the final pulse, indicating that any perturbation to the pulse frequency or duration would have rapid quantitative effects on the levels of the gene products (72). A similar pulsatile motif, following in vitro exposure to a pulsatile GC treatment, on the transcription of GR-regulated genes has been reported for sulfite oxidase, a mitochondrial enzyme involved in cellular energy production, GC-induced leucine zipper, a transcription factor, tissue transglutaminase, a protein regulating cytoskeletal properties and involved in neurodegenerative processes and melatonin receptor 1B. That pulsatile motif of gene expression is lost if the GC rhythm switches from pulsatile to non-pulsatile or if natural GCs are replaced with synthetic ones with a huge potency for GRs, like dexamethasone (73). Increased sensitivity to GC pulsatility has also been observed for serum/GC regulated kinase 1, implicated in the 
regulation of ion channels, cell survivability and longterm memory formation, and pro-opiomelanocortin, the ACTH precursor, in pituitary but not in prefrontal cortex of rodents (74). Finally, gene ontology analysis of the transcriptome of HeLa cells contrasting in vitro pulsatile vs continuous cortisol exposure revealed expression differences in genes involved in cytoskeletal homeostasis and cell adhesion (75).

Aside the delayed, genomic events synchronised with the dynamic hormonal oscillations, rapid, non-nuclear events have also been described, indicating that spikes in GC concentrations can very quickly regulate neural processes, like neurotransmission and synaptic plasticity in a brain region-specific manner. For instance, GCs enhance transiently the frequency of miniature excitatory postsynaptic potentials in CA1 (hippocampal) pyramidal neurons, pointing to a hormone-dependent enhancement of glutamate release probability via a pathway involving membrane-located MRs (76). A similar phenomenon has been observed in the basolateral amygdala; contrary to the hippocampus, though, the upregulation in glutamatergic neurotransmission is long lasting and greatly affects the responsiveness to subsequent surges of GCs in a GR-dependent manner (77). More recent studies additionally showed that the frequency of the hormonal pulses differentially regulate the frequency of miniature excitatory postsynaptic currents, AMPA receptor trafficking and the induction of long-term potentiation in cultures of hippocampal neurons and dorsal hippocampal slices from rodent brains $(78,79)$. Related to this, GC-activated membrane-associated GRs promote the interaction between phospho-CREB and CREB-binding proteins, leading to epigenomic events (histone acetylation) in both the hippocampus and insular cortex, following training on object recognition, associated with memory consolidation (80). Finally, it has been illustrated that acute psychological stress resulted in the upregulation of the neuroplasticity-associated immediate-early genes c-Fos and Egr-1 in granule neurons of the dentate gyrus (hippocampus), following the serine-10 phosphorylation and lysine-14 acetylation in histone $\mathrm{H} 3$, which were induced by the activation of the nuclear kinases MSK1 and Elk-1. The latter required a rapid protein-protein interaction between the phosphorylated ERK1/2 and GC-activated GRs, linked to long-lasting behavioural responses to stress (81).

Eventually, GC pulsatility affects behavioural responses (82) and the readiness of the stress system for an effective mobilisation. Emotional and motor responses to external stressors or aggressive challenges are more prominent when the cue coincides with the rising phase of the ultradian GC pulse compared to the falling phase (83). Moreover, disruption of the normal ultradian GC rhythm has been associated with changes in the stress responsiveness and a dissociation between hormonal and behavioural responses to stress (84). Furthermore, in silico approaches also strongly suggest that the presence of pulsatility in homeostatic HPA function confers the potential for increased acute stress responsiveness (85).

\section{How does brain physiology incorporate the different aspects of GC rhythmicity?}

In parallel to findings in peripheral tissues $(9,38,86)$, which possess local circadian clocks regulating the diurnal variation in GC sensitivity, similar mechanisms occur in different brain regions, that could modulate fundamental circadian processes, like metabolism, oxidative stress response, DNA repair and autophagy (at a cellular level), or memory, sleep-awake cycles, mood and eventually behaviour (at a systems level) (87). Subject to brain region-specific and (in some cases possibly) temporally varying hormonal sensitivity, GC pulsatility optimises the circadian sustainability of GC stimulation, applies a temporal filter on GC effects (especially those mediated by GRs and non-nuclear MRs), as well as keeps the nervous system competent for properly integrating external stimuli or changes in internal states.

A typical example on the sustainability of GC stimulation is the fact that GC pulsatility preserves the stock of available mature transcript of the period- 1 gene in hippocampal cells (72), as we mentioned earlier. Perhaps though, the most crucial aspect of GC pulsatility is that it offers the brain an extended temporal window (on a daily basis) for effective, immediate responses to internal or external challenges (83), as well as successful, longterm adaptation. Pulsatility enables the maintenance of a reactive and responsive signalling system which is not downregulated by constant receptor activation. Moreover, in the context of confronting a challenging situation, the subsequent activation of such a range of different types of GC-sensitive receptors contributes to an ability to have temporally specific responses to a stressor: non-nuclear MRs seem to be necessary for coordinating the initial brain response to stress (in accordance with their fast, non-genomic actions), while at a later stage, GRs initiate the processes responsible for reestablishing homeostasis and mediating the successful neurobehavioral adaptations to increase effectiveness towards confronting future incidences (60). Furthermore, outside the context of stress 
induction, the frequent GC surges increase the probability of GC stimulation coinciding with (or dissociating from) activation by other, interacting biomolecules, with which GCs have additive or nullifying effects. A prominent example is brain-derived neurotrophic factor (88).

Finally, it is worth mentioning that body states accompanied by disruptions of GC pulsatility, leading to a prolonged exposure to high GC levels, have been linked to a weakened GR activation. For instance, rapid GR-dependent negative feedback regulation of ACTH release under basal conditions or acute stress (24) is reduced in major depression, a condition accompanied with an overactive HPA axis (89). Other examples involve the reduction of immune system's sensitivity to GCs' immunosuppressive effects during chronic psychological stress (90) or the selective downregulation of hippocampal GRs under sustained stress in rodents and non-human primates (91) or after the experimental induction of viral encephalitis in rats (92).

The GC ultradian rhythm appears to provide a very important neurobiological signal which differentially regulates the gene expression profile and various second messenger systems of intracellular signal transduction of brain cells and, eventually, impacts cognition, behaviour and stress responsiveness (Fig. 2). Similar to the hormone's circadian rhythm, disruption of the normal characteristics of the ultradian rhythm have, very recently, been linked to animal models of neuropsychiatric disease (93). But what are the clinical implications of all these? Does GC rhythmicity have a similar significance for human brain function?

\section{Clinical studies: is GC rhythmicity important for the human brain?}

\section{Effects of oral GC administration on the human brain}

Before focusing on the relevance of GC rhythmicity for the human brain function, we need to establish which domains of human cognition are influenced by GC input. A number of clinical trials in healthy subjects, using functional neuroimaging (fMRI) techniques and psychological experiments, have added valuable insights. In these studies, participants were receiving one dose of hydrocortisone or placebo, usually orally, and subsequently underwent some form of a cognitive or psychological task, measuring an aspect of human brain function, with or without the concurrent application of an fMRI protocol. The timepoints for applying the outcome measures after hydrocortisone administration were either 60-120 min, reflecting the rapid effects of the hormone, and/ or 180-240 min, reflecting the delayed effects of the hormone.

Under such experimental settings, it has been shown that GCs interfere with various systems of memory processing. For instance, it has been shown that (i) intravenous $100 \mathrm{mg}$ hydrocortisone infusion acutely increases the involvement of the prefrontal and parietal cortex, while reducing the involvement of the hippocampus, in a working memory task (n-back) (94), (ii) $10 \mathrm{mg}$ of hydrocortisone improves working memory performance in the same kind of task (n-back) $240 \mathrm{~min}$ after their per os administration, an effect related to increased neuronal activity in the dorsolateral prefrontal cortex (95), (iii) $20 \mathrm{mg}$ of hydrocortisone reduce prefrontal and hippocampal responses during memory encoding sessions $180 \mathrm{~min}$ after their per os administration (96) and (iv) $10 \mathrm{mg}$ of oral hydrocortisone uptake increase the neural processing of the anteromedial prefrontal cortex during sessions of autobiographical memory retrieval 60 min post administration (97).

Under such experimental settings, it has been also illustrated that GCs facilitate the neurocognitive transitions between the unstressed brain, its stressed and its post-stress state. In particular, data suggest that (i) cortisol levels are positively correlated with a functional coupling between amygdala and medial prefrontal cortex under relatively non-stressful conditions (98), but negatively correlated with a sustained functional connectivity between amygdala and hippocampus during the poststress period (99), (ii) $10 \mathrm{mg}$ of hydrocortisone reduce the interaction of amygdala with areas responsible for initiating and preserving a stress response (locus coeruleus, hypothalamus, and hippocampus), while they increase the interaction of amygdala with areas associated with executive functions (middle frontal and temporal gyrus) $105 \mathrm{~min}$ after their per os administration (100), (iii) a stressinduced increase in GC levels augments the functional coupling between amygdala and dorsal striatum (101), but reduces the learning-related hippocampal processing in an MR-dependent manner, during a combined trace and delay fear conditioning paradigm $(102,103)$.

Finally, under such experimental settings, it has been shown that GCs interfere with emotional processing. Thus, (i) $10 \mathrm{mg}$ of hydrocortisone reduces amygdala responsivity to emotional faces 75 and $285 \mathrm{~min}$ after their per os administration, while slowly strengthening the functional coupling between amygdala and medial prefrontal cortex, leading to a normalised response to the negative 
emotional stimuli (104) and (ii) $10 \mathrm{mg}$ of hydrocortisone modulates the impact of emotional distraction of attentive processing in a time-specific manner; $60 \mathrm{~min}$ after per os administration, there is increased emotional interference (associated with reduced amygdala inhibition to aversive words and enhanced amygdala connectivity with frontoparietal brain regions), but later on (270 min after their per os administration) decreased overall activity in the cuneus, possibly indicating reduced bottom-up attentional processing, and disrupted amygdala connectivity to the insula, potentially reducing emotional interference (105).

Given these findings on GC involvement in memory, emotional processing and stress-related neural processing, it is of no surprise that one of the most well-described effects of GCs on the human brain (supported by integrative research, combining preclinical experimentation and clinical studies) involves the modulation of the mnemonic processing of emotionally arousing experiences (106). In the context of a stress response, GCs enhance memory consolidation and impair memory retrieval. This phenomenon is associated with a shift from a hippocampus-controlled to a dorsal striatumcontrolled cognitive processing. This shift requires the involvement of the amygdala, and GCs enhance in a rapid, GR-dependent manner the noradrenaline-induced rise in intraneuronal cAMP levels in the basolateral amygdala, which upregulate the protein kinase A-dependent downstream pathways, involving among others the endocannabinoid system (107).

GCs clearly exert important effects over the human brain function, as anticipated by the strong preclinical evidence presented before. But is their rhythmicity so important from a clinical point of view as well?

\section{Observational studies on the relationship between GC dysrhythmicity and brain pathology}

The most obvious sources of GC dysrhythmicity are conditions directly impacting GC biosynthesis; either adrenal insufficiency (for instance Addison's disease, $\mathrm{AD}$ or congenital adrenal hyperplasia (CAH)), leading to hypocortisolism or Cushing's syndrome, leading to hypercortisolism. In the former cases, GCs are replaced orally, in a manner that does not replicate either the circadian or the ultradian rhythm of the hormone (3). Cushing's syndrome has been correlated with brain atrophy, memory impairment and depression, while correction of hypercortisolism (but not the optimal daily GC rhythm), though attenuating brain atrophy, does not successfully reverse cognitive deficits $(108,109)$.
In relation to these results, a recent study highlighted the presence of functional alterations in emotional processing of amygdala and hippocampus in adolescents with chronic endogenous hypercortisolemia due to Cushing's syndrome, that are not associated with affective or memory symptoms (110). These trends have been recently confirmed by a large review of 19 related studies, covering 339 patients with Cushing's syndrome (111). On the other hand, hypocortisolism also exerts damaging effects centred on the corticolimbic areas of the brain, and age seems to be reversely associated with the degree of brains' susceptibility to absence of GCs; there is some evidence that $\mathrm{CAH}$ is correlated with decreased growth, development and dysregulated function of the amygdala $(112,113)$, disrupted white matter integrity $(114)$, bilateral periventricular white matter hyperintensities and corticosubcortical atrophy $(115,116)$, as well as cognitive deficits $(117,118)$.

Brain pathology however that is totally separate from the circuits regulating HPA activity can also lead to GC dysrhythmicity. In a study of stroke patients with rightsided infarction (119), researchers observed an altered tonic and phasic cortisol secretion and a damaged stress response compared to stroke patients with left-sided infarction or healthy age-matched controls.

Where things become more complicated are in various neuropsychiatric disorders, where it is difficult to establish whether GC dysrhythmicity has a causal relationship with the neuropathological sequel or whether it is the result of the neuropathological process. In such cases, a vicious cycle develops between these two variables. Such conditions include patients with Alzheimer's disease, Parkinson's disease and post-traumatic stress disorder, which show disruptions in the circadian and ultradian GC rhythmicity $(26,120,121)$, subgroups of patients with major depression, fibromyalgia and chronic fatigue syndrome, with the HPA being overactive in the former (122) and malfunctioning in the two latter cases (123, $124,125)$. Very recently, Vargas et al. (126) proposed that a disrupted ultradian cortisol rhythm could be a potential neurobiological substrate for chronic insomnia.

It is also worth mentioning that genetic variations and epigenomic mechanisms (for instance, DNA methylation) related to early-life events impact GR expression and its sensitivity to GCs, consequently altering the temporal characteristics and the strength of the GR-mediated negative feedback control of GCs on the pituitary and hypothalamus. Based on our biomodelling approaches (37), the lower the sensitivity of GR-mediated signalling to GCs, the greater the amplitude of the hormonal pulses, 
especially around the period of the circadian peak. Interindividual differences in GR sensitivity will therefore lead to altered physiological GC rhythms and could affect neurodevelopment, predisposing towards certain behavioural phenotypes and psychopathology (127).

In addition to these endogenous perturbations the most frequent clinical causes of GC dysrhythmicity is the exogenous, systemic administration of synthetic GCs. These interfere with GC signalling cascades, as well as disrupt both the physiological feedforward-feedback interplay between adrenal glands and pituitary, which gives rise to the ultradian rhythm, and the negative feedback effect of natural GCs on the hypothalamus, which modulates the circadian properties of the hormonal rhythm. Are GC-based therapies then linked to neuropsychiatric symptomatology?

\section{Is there a relationship between GC-based therapeutics and neuropsychiatric symptomatology?}

The prolonged use of GC-based regimes and/or their administration in high doses is accompanied by numerous adverse effects, including neuropsychiatric (128). The list of symptoms spans almost every kind of cognitive or emotional disturbance: memory impairments (declarative memory, working memory and explicit memory), agitation, anxiety, fear, hypomania, irritability, lethargy, mood lability and psychosis. Individuals who develop psychiatric manifestations on short courses of GCs most commonly report euphoria, while those on long-term therapy tend to develop depressive symptoms. The timing of GC administration has been strongly linked to sleep disturbances as well.

The most striking finding, however, is the poor clinical outcome in the simplest therapeutic situation when GCs are prescribed as replacement therapy in primary adrenocortical insufficiency (129), even when the daily amount of GCs administered does not differ from that produced by the human body under physiological conditions. In 2002, Løvås et al. (130) reported that Addisonian patients receiving substitution therapy (cortisone acetate and fludrocortisone) had reduced general health perception and vitality, and increased fatigue, as assessed by psychological self-evaluation scales (Short Form 36 and the Fatigue questionnaires). Recent studies, over a decade later, confirmed these observations, that health-related quality of life is significantly impaired in Addisonian patients compared with the age-matched and gender-matched general population, despite the proper use of the recommended oral hydrocortisone doses $(131,132)$. The mental fatigue, accounting for a significant portion of these patient's poorer quality of life, is characterised by higher prevalence of mood disorders (mainly depression), memory impairment and sleep disorders (133). Similar findings have been reported in patients with Cushing's syndrome after long-term remission, where the health-related quality of life remains impaired regardless of aetiology, presence of hormonal deficiencies and different treatment strategies (134). Therefore, the fact that restoration of the physiological GC levels might not be sufficient for them to exert their normal neurobiological effects provides support for the idea that the pattern of GC rhythmicity may be crucial even for basic mood regulation.

\section{What do GC replacement therapies tell us about the significance of GC rhythmicity for the human brain?}

Current protocols on GC replacement in states of adrenal insufficiency recommend the oral administration of hydrocortisone 2-3 times daily (or longer acting synthetic prednisolone once daily in the morning), with the morning dose being at least $50 \%$ of the total daily GC dose. Such a pattern of GC administration cannot replicate either the circadian or the ultradian rhythm of the hormone. For example, the natural circadian peak of GCs in human anticipates the need for morning activities by commencing secretion several hours prior the morning awaking, whereas the morning dose of oral replacement therapy (which is responsible of creating the diurnal peak in patients with adrenal insufficiency) is taken postawaking resulting in a hormonal peak about one hour later. Furthermore, three doses of oral GC replacement create a form of hormonal ultradian rhythm characterised by a much smaller number of daily pulses, with a much longer duration and inter-pulse intervals than normally present. This raises the question whether an improvement in the pharmacological replication of the circadian and ultradian rhythm of GC substitution could also be followed by an improvement in clinical markers of brain function in patients with adrenal insufficiency, which would also be a strong indication of the neurobiological significance of GC rhythmicity for the human brain physiology.

Five clinical studies and three case reports have been published over the last decade, comparing the administration of hydrocortisone by continuous smooth subcutaneous infusion mimicking the diurnal but not the ultradian pattern of plasma cortisol (SCHI), with 
currently considered optimal oral therapy (OT) (135) in patients with $\mathrm{AD}$ or $\mathrm{CAH}$. The main focus of these studies was markers on the endocrine and metabolic state of the patients (136) together with other questions related to personalised medicine $(137,138,139)$. Compared to OT, the SCHI was found to improve the self-perceived mood, feelings of fatigue, vitality and physical function in Addisonian patients, while not affecting subjective or objective measures of sleep behaviour at 12 weeks (140). These favourable effects developed over a period of many weeks both in this and a similar concurrent clinical trial (141). A similar, favourable effect in markers of fatigue, mood and vitality has been observed in SCHI over OT in CAH patients at 6 months (142), which were maintained at 18 months (143).

More direct evidence on the neurobiological importance of GC rhythmicity for the human brain has been published recently. We created a human model of adrenal insufficiency by pharmacologically blocking GC biosynthesis (oral administration of metyrapone three times daily) and replacing the hormone in three different modes, using either (i) oral treatment (OT), (ii) constant subcutaneous infusion (SCHI) or (iii) a novel, subcutaneous, pump-based method, delivering different size pulses of hydrocortisone every $3 \mathrm{~h}$, which reproduced both the natural circadian and ultradian patterns of cortisol. We then examined the neurocognitive effects of these different GC rhythms using functional neuroimaging techniques and a set of cognitive and behavioural tests, markers of sleep behaviour, working memory and emotional processing, in a randomised, double-blind, placebo-controlled, crossover study (144). We were able to demonstrate that non-pulsatile GC exposure (i.e. SCHI) correlates with poorer quality of sleep and that both SCHI and OT were associated with poorer working memory performance under increased

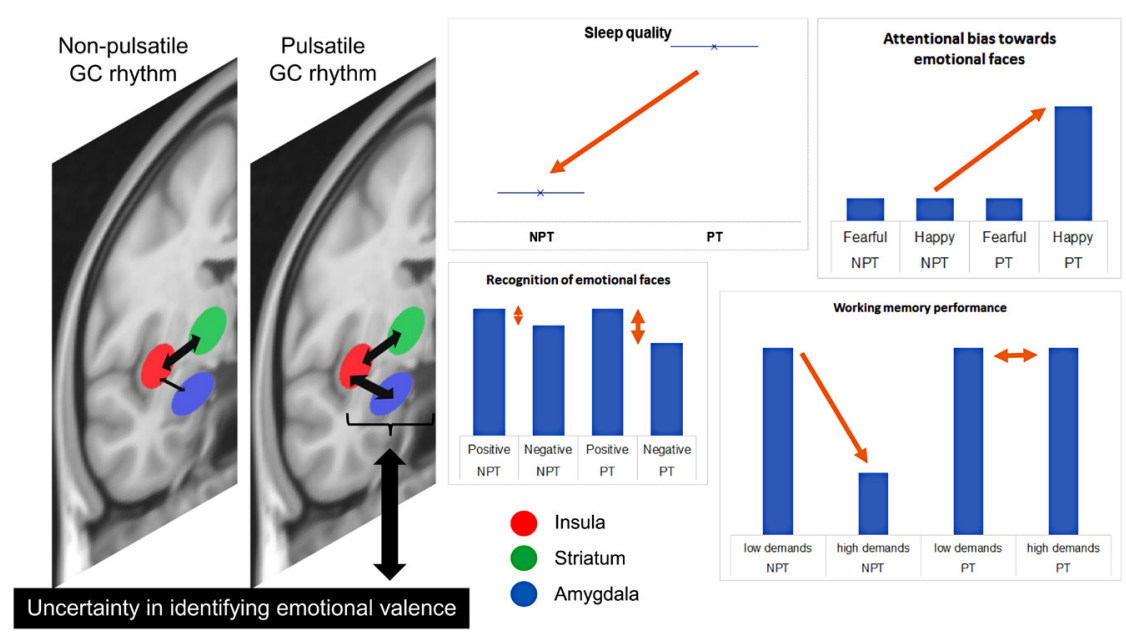

\section{Figure 3}

The importance of glucocorticoid (GC) pulsatility for the human brain. Comparing circadian patterns of cortisol infused in physiological pulses (PT) with the same dose of circadian cortisol infused as a smooth infusion (non-pulsatile infusion, NPT), brain function was investigated by neuroimaging and psychological measures, focusing on three domains: sleep behaviour, working memory and, primarily, emotional processing. Subjects on the NPT experienced poorer quality of sleep and working memory performance compared to the PT arm of the study. Moreover, subjects on PT preferentially engaged with positively valenced facial expressions and showed a reduced accuracy in correctly discriminating between negatively valenced human faces (i.e. increased ambiguity in perceiving negative emotional stimuli), a response similar to that seen in healthy subjects and depressed patients receiving antidepressants. The between-treatment group changes in emotional ambiguity were linked to changes in the underlying role and functional connectivity among corticolimbic regions, mediating emotional processing. While in PT the functional connectivity between amygdala and insula, and striatum and insula, during encoding of emotional cues is strong, and the intensity of the neural processing in all these structures (especially for the amygdala) is associated with the degree of uncertainty in discriminating between emotional valences, this association is lost in NPT, combined with a reduction in the functional connectivity between amygdala and insula. Collectively, these data support the notion that GC pulsatility may facilitate the optimal functioning of neural mechanisms underlying emotional processing, and perhaps a protective mechanism against susceptibility to depression. 
cognitive demands. Moreover, we were able to illustrate that different patterns of plasma GC oscillations have a differential impact on the participation and functional connectivity of brain regions underlying emotional processing (amygdala, dorsal striatum, insula, orbitofrontal cortex) affecting attentional bias to and recognition accuracy of emotional cues (145). These data support the notion that changes in GC rhythmicity can modulate the neural dynamics regulating mood and anxiety in man (Fig. 3).

Future studies should systematically explore the clinical utility of manipulating features of GC rhythmicity both to improve personalised treatment strategies and neuropsychiatric disease subclassification. We believe a better chronobiological approach to GC therapeutics is urgently needed.

\section{Declaration of interest}

The authors declare that there is no conflict of interest that could be perceived as prejudicing the impartiality of this review.

\section{Funding}

The study on glucocorticoids has been supported by Research Grants from Wellcome Trust (Grant No 089647/Z/09/Z) and Medical Research Council (DCS Grant No MR/J0125481/1).

\section{References}

1 Hill MR, Szefler SJ, Ball BD, Bartoszek M \& Brenner AM. Monitoring glucocorticoid therapy: a pharmacokinetic approach. Clinical Pharmacology and Therapeutics 199048 390-398. (https://doi. org/10.1038/clpt.1990.167)

2 Rhen T \& Cidlowski JA. Antiinflammatory action of glucocorticoids - new mechanisms for old drugs. New England Journal of Medicine 2005353 1711-1723. (https://doi.org/10.1056/NEJMra050541)

3 Crown A \& Lightman S. Why is the management of glucocorticoid deficiency still controversial: a review of the literature. Clinical Endocrinology 200563 483-492. (https://doi.org/10.1111/j.13652265.2005.02320.x)

4 Buckley TM \& Schatzberg AF. On the interactions of the hypothalamic-pituitary-adrenal (HPA) axis and sleep: normal HPA axis activity and circadian rhythm, exemplary sleep disorders. Journal of Clinical Endocrinology and Metabolism 200590 3106-3114. (https:// doi.org/10.1210/jc.2004-1056)

5 Van Cauter E, Leproult R \& Kupfer DJ. Effects of gender and age on the levels and circadian rhythmicity of plasma cortisol. Journal of Clinical Endocrinology and Metabolism 199681 2468-2473. (https:// doi.org/10.1210/jcem.81.7.8675562)

6 Bartels M, Van den Berg M, Sluyter F, Boomsma DI \& de Geus EJC. Heritability of cortisol levels: review and simultaneous analysis of twin studies. Psychoneuroendocrinology 200328 121-137. (https://doi. org/10.1016/S0306-4530(02)00003-3)

7 Spiga F, Walker JJ, Terry JR \& Lightman SL. HPA axis-rhythms. Comprehensive Physiology 20144 1273-1298. (https://doi. org/10.1002/cphy.c140003)
8 Lightman SL, Windle RJ, Ma XM, Harbuz MS, Shanks NM, Julian MD, Wood SA, Kershaw YM \& Ingram CD. Hypothalamicpituitary-adrenal function. Archives of Physiology and Biochemistry 2002110 90-93. (https://doi.org/10.1076/apab.110.1.90.899)

9 Son GH, Cha HK, Chung S \& Kim K. Multimodal regulation of circadian glucocorticoid rhythm by central and adrenal clocks. Journal of the Endocrine Society 20182 444-459. (https://doi. org/10.1210/js.2018-00021)

10 Jacobson L \& Sapolsky R. The role of the hippocampus in feedback regulation of the hypothalamic-pituitary-adrenocortical axis. Endocrine Reviews 199112 118-134. (https://doi.org/10.1210/edrv-122-118)

11 Herman JP, Ostrander MM, Mueller NK \& Figueiredo H. Limbic system mechanisms of stress regulation: hypothalamo-pituitaryadrenocortical axis. Progress in Neuro-Psychopharmacology and Biological Psychiatry 200529 1201-1213. (https://doi.org/10.1016/j. pnpbp.2005.08.006)

12 Fulkerson WJ, Sawyer GJ \& Gow CB. Investigations of ultradian and circadian rhythms in the concentration of cortisol and prolactin in the plasma of dairy cattle. Australian Journal of Biological Sciences 1980 33 557-561. (https://doi.org/10.1071/BI9800557)

13 Lefcourt AM, Bitman J, Kahl S \& Wood DL. Circadian and ultradian rhythms of peripheral cortisol concentrations in lactating dairy cows. Journal of Dairy Science 199376 2607-2612. (https://doi.org/10.3168/ jds.S0022-0302(93)77595-5)

14 Cudd TA, LeBlanc M, Silver M, Norman W, Madison J, KellerWood M \& Wood CE. Ontogeny and ultradian rhythms of adrenocorticotropin and cortisol in the late-gestation fetal horse. Journal of Endocrinology 1995144 271-283. (https://doi.org/10.1677/ joe.0.1440271)

15 Sarnyai Z, Veldhuis JD, Mello NK, Mendelson JH, Erös-Sarnyai M, Mercer G, Gelles H \& Kelly M. The concordance of pulsatile ultradian release of adrenocorticotropin and cortisol in male rhesus monkeys. Journal of Clinical Endocrinology and Metabolism 199580 54-59. (https://doi.org/10.1210/jcem.80.1.7829639)

16 Holaday JW, Martinez HM \& Natelson BH. Synchronized ultradian cortisol rhythms in monkeys: persistence during corticotropin infusion. Science 1977198 56-58. (https://doi.org/10.1126/ science.197603)

17 Ingram JR, Matthews LR, Carragher JF \& Schaare PR. Plasma cortisol responses to remote adrenocorticotropic hormone (ACTH) infusion in free-ranging red deer (Cervus elaphus). Domestic Animal Endocrinology 199714 63-71. (https://doi.org/10.1016/S07397240(96)00095-1)

18 Fulkerson WJ \& Tang BY. Ultradian and circadian rhythms in the plasma concentration of cortisol in sheep. Journal of Endocrinology 197981 135-141. (https://doi.org/10.1677/joe.0.0810135)

19 Follenius M, Simon C, Brandenberger G \& Lenzi P. Ultradian plasma corticotropin and cortisol rhythms: time-series analyses. Journal of Endocrinological Investigation 198710 261-266. (https://doi. org/10.1007/BF03348128)

20 Spiga F, Waite EJ, Liu Y, Kershaw YM, Aguilera G \& Lightman SL. ACTH-dependent ultradian rhythm of corticosterone secretion. Endocrinology 2011152 1448-1457. (https://doi.org/10.1210/ en.2010-1209)

21 Waite EJ, Mckenna M, Kershaw Y, Walker JJ, Cho K, Piggins HD \& Lightman SL. Ultradian corticosterone secretion is maintained in the absence of circadian cues. European Journal of Neuroscience 201236 3142-3150. (https://doi.org/10.1111/j.1460-9568.2012.08213.x)

22 Pasquali R, Biscotti D, Spinucci G, Vicennati V, Genazzani AD, Sgarbi L \& Casimirri F. Pulsatile secretion of ACTH and cortisol in premenopausal women: effect of obesity and body fat distribution. Clinical Endocrinology 199848 603-612. (https://doi.org/10.1046/ j.1365-2265.1998.00458.x)

23 Gavrila A, Peng CK, Chan JL, Mietus JE, Goldberger AL \& Mantzoros CS. Diurnal and ultradian dynamics of serum adiponectin 
in healthy men: comparison with leptin, circulating soluble leptin receptor, and cortisol patterns. Journal of Clinical Endocrinology and Metabolism 200388 2838-2843. (https://doi.org/10.1210/jc.2002021721)

24 Russell GM, Henley DE, Leendertz J, Douthwaite JA, Wood SA, Stevens A, Woltersdorf WW, Peeters BWMM, Ruigt GSF, White A et al. Rapid glucocorticoid receptor-mediated inhibition of hypothalamic-pituitary-adrenal ultradian activity in healthy males. Journal of Neuroscience 201030 6106-6115. (https://doi.org/10.1523/ JNEUROSCI.5332-09.2010)

25 Lightman S \& Terry JR. The importance of dynamic signalling for endocrine regulation and drug development: relevance for glucocorticoid hormones. Lancet Diabetes and Endocrinology 20142 593-599. (https://doi.org/10.1016/S2213-8587(13)70182-7)

26 Hartmann A, Veldhuis JD, Deuschle M, Standhardt H \& Heuser I. Twenty-four hour cortisol release profiles in patients with Alzheimer's and Parkinson's disease compared to normal controls: ultradian secretory pulsatility and diurnal variation. Neurobiology of Aging 1997 18 285-289. (https://doi.org/10.1016/S0197-4580(97)80309-0)

27 Young EA, Carlson NE \& Brown MB. Twenty-four-hour ACTH and cortisol pulsatility in depressed women. Neuropsychopharmacology 200125 267-276. (https://doi.org/10.1016/S0893-133X(00)00236-0)

28 Crofford LJ, Young EA, Engleberg NC, Korszun A, Brucksch CB, McClure LA, Brown MB \& Demitrack MA. Basal circadian and pulsatile ACTH and cortisol secretion in patients with fibromyalgia and/or chronic fatigue syndrome. Brain, Behavior, and Immunity 2004 18 314-325. (https://doi.org/10.1016/j.bbi.2003.12.011)

29 Henley DE, Russell GM, Douthwaite JA, Wood SA, Buchanan F, Gibson R, Woltersdorf WW, Catterall JR \& Lightman SL. Hypothalamic-pituitary-adrenal axis activation in obstructive sleep apnea: the effect of continuous positive airway pressure therapy. Journal of Clinical Endocrinology and Metabolism 200994 4234-4242. (https://doi.org/10.1210/jc.2009-1174)

30 Lightman SL, Wiles CC, Atkinson HC, Henley DE, Russell GM, Leendertz JA, McKenna MA, Spiga F, Wood SA \& ConwayCampbell BL. The significance of glucocorticoid pulsatility. European Journal of Pharmacology 2008583 255-262. (https://doi. org/10.1016/j.ejphar.2007.11.073)

31 Windle RJ, Wood SA, Shanks N, Lightman SL \& Ingram CD. Ultradian rhythm of basal corticosterone release in the female rat: dynamic interaction with the response to acute stress. Endocrinology 1998139 443-450. (https://doi.org/10.1210/endo.139.2.5721)

32 Tapp WN, Holaday JW \& Natelson BH. Ultradian glucocorticoid rhythms in monkeys and rats continue during stress. American Journal of Physiology-Regulatory, Integrative and Comparative Physiology 1984247 R866-R871. (https://doi.org/10.1152/ ajpregu.1984.247.5.R866)

33 Rankin J, Walker JJ, Windle R, Lightman SL \& Terry JR. Characterizing dynamic interactions between ultradian glucocorticoid rhythmicity and acute stress using the phase response curve. PLOS ONE 20127 e30978. (https://doi.org/10.1371/journal. pone.0030978)

34 Gjerstad JK, Lightman SL \& Spiga F. Role of glucocorticoid negative feedback in the regulation of HPA axis pulsatility. Stress 201821 403-416. (https://doi.org/10.1080/10253890.2018.1470238)

35 Glantz SA, Luetscher JA, Day RP \& Perloff M. A compartment description for cortisol secretion, distribution, binding, and metabolism in man. IEEE Transactions on Biomedical Engineering 1976 23 36-44. (https://doi.org/10.1109/TBME.1976.324613)

36 Gupta S, Aslakson E, Gurbaxani BM \& Vernon SD. Inclusion of the glucocorticoid receptor in a hypothalamic pituitary adrenal axis model reveals bistability. Theoretical Biology and Medical Modelling 20074 8. (https://doi.org/10.1186/1742-4682-4-8)

37 Walker JJ, Terry JR \& Lightman SL. Origin of ultradian pulsatility in the hypothalamic-pituitary-adrenal axis. Proceedings of the Royal
Society B: Biological Sciences 2010277 1627-1633. (https://doi. org/10.1098/rspb.2009.2148)

38 So AYL, Bernal TU, Pillsbury ML, Yamamoto KR \& Feldman BJ. Glucocorticoid regulation of the circadian clock modulates glucose homeostasis. PNAS 2009106 17582-17587. (https://doi.org/10.1073/ pnas.0909733106)

39 Begliuomini S, Lenzi E, Ninni F, Casarosa E, Merlini S, Pluchino N, Valentino V, Luisi S, Luisi M \& Genazzani AR. Plasma brain-derived neurotrophic factor daily variations in men: correlation with cortisol circadian rhythm. Journal of Endocrinology 2008197 429-435. (https://doi.org/10.1677/JOE-07-0376)

40 Malek ZS, Sage D, Pévet P \& Raison S. Daily rhythm of tryptophan hydroxylase-2 messenger ribonucleic acid within raphe neurons is induced by corticoid daily surge and modulated by enhanced locomotor activity. Endocrinology 2007148 5165-5172. (https://doi. org/10.1210/en.2007-0526)

41 Lamont EW, Robinson B, Stewart J \& Amir S. The central and basolateral nuclei of the amygdala exhibit opposite diurnal rhythms of expression of the clock protein Period2. PNAS 2005102 4180-4184. (https://doi.org/10.1073/pnas.0500901102)

42 Liston C, Cichon JM, Jeanneteau F, Jia Z, Chao MV \& Gan WB. Circadian glucocorticoid oscillations promote learning-dependent synapse formation and maintenance. Nature Neuroscience 201316 698-705. (https://doi.org/10.1038/nn.3387)

43 Jacobs N, Myin-Germeys I, Derom C, Delespaul P, van Os J \& Nicolson NA. A momentary assessment study of the relationship between affective and adrenocortical stress responses in daily life. Biological Psychology 200774 60-66. (https://doi.org/10.1016/j. biopsycho.2006.07.002)

44 Polk DE, Cohen S, Doyle WJ, Skoner DP \& Kirschbaum C. State and trait affect as predictors of salivary cortisol in healthy adults. Psychoneuroendocrinology 200530 261-272. (https://doi. org/10.1016/j.psyneuen.2004.08.004)

45 Putnam KM, Pizzagalli DA, Gooding DC, Kalin NH \& Davidson RJ. Neural activity and diurnal variation of cortisol: evidence from brain electrical tomography analysis and relevance to anhedonia. Psychophysiology 200845 886-895. (https://doi.org/10.1111/j.14698986.2008.00697.x)

46 Ikeda Y, Kumagai H, Skach A, Sato M \& Yanagisawa M. Modulation of circadian glucocorticoid oscillation via adrenal opioid-CXCR7 signaling alters emotional behavior. Cell 2013155 1323-1336. (https://doi.org/10.1016/j.cell.2013.10.052)

47 Son GH, Chung S, Choe HK, Kim HD, Baik SM, Lee H, Lee HW, Choi S, Sun W, Kim H et al. Adrenal peripheral clock controls the autonomous circadian rhythm of glucocorticoid by causing rhythmic steroid production. PNAS 2008105 20970-20975. (https://doi. org/10.1073/pnas.0806962106)

48 Moon JH, Cho CH, Son GH, Geum D, Chung S, Kim H, Kang SG, Park YM, Yoon HK, Kim L et al. Advanced circadian phase in mania and delayed circadian phase in mixed mania and depression returned to normal after treatment of bipolar disorder. EBioMedicine 201611 285-295. (https://doi.org/10.1016/j.ebiom.2016.08.019)

49 Yoshida M, Koyanagi S, Matsuo A, Fujioka T, To H, Higuchi S \& Ohdo S. Glucocorticoid hormone regulates the circadian coordination of micro-opioid receptor expression in mouse brainstem. Journal of Pharmacology and Experimental Therapeutics 2005 315 1119-1124. (https://doi.org/10.1124/jpet.105.091488)

50 Kalafatakis K, Russell GM, Zarros A \& Lightman SL. Temporal control of glucocorticoid neurodynamics and its relevance for brain homeostasis, neuropathology and glucocorticoid-based therapeutics. Neuroscience and Biobehavioral Reviews 201661 12-25. (https://doi. org/10.1016/j.neubiorev.2015.11.009)

51 Qian X, Droste SK, Lightman SL, Reul JMHM \& Linthorst ACE. Circadian and ultradian rhythms of free glucocorticoid hormone are highly synchronized between the blood, the subcutaneous tissue, 
and the brain. Endocrinology 2012153 4346-4353. (https://doi. org/10.1210/en.2012-1484)

52 Droste SK, De Groote L, Lightman SL, Reul JMHM \& Linthorst ACE. The ultradian and circadian rhythms of free corticosterone in the brain are not affected by gender: an in vivo microdialysis study in wistar rats. Journal of Neuroendocrinology 200921 132-140. (https:// doi.org/10.1111/j.1365-2826.2008.01811.x)

53 Droste SK, De Groote L, Atkinson HC, Lightman SL, Reul JMHM \& Linthorst ACE. Corticosterone levels in the brain show a distinct ultradian rhythm but a delayed response to forced swim stress. Endocrinology 2008149 3244-3253. (https://doi.org/10.1210/ en.2008-0103)

54 Bhake RC, Leendertz JA, Linthorst ACE \& Lightman SL. Automated 24-hours sampling of subcutaneous tissue free cortisol in humans. Journal of Medical Engineering and Technology 201337 180-184. (https://doi.org/10.3109/03091902.2013.773096)

55 Grillo C, Vallee S, McEwen BS \& De Nicola AF. Properties and distribution of binding sites for the mineralocorticoid receptor antagonist [3H]ZK 91587 in brain. Journal of Steroid Biochemistry 1990 35 11-15. (https://doi.org/10.1016/0022-4731(90)90138-I)

56 Patel PD, Lopez JF, Lyons DM, Burke S, Wallace M \& Schatzberg AF. Glucocorticoid and mineralocorticoid receptor mRNA expression in squirrel monkey brain. Journal of Psychiatric Research 200034 383-392. (https://doi.org/10.1016/S0022-3956(00)00035-2)

57 Agarwal MK, Mirshahi F, Mirshahi M \& Rostene W. Immunochemical detection of the mineralocorticoid receptor in rat brain. Neuroendocrinology 199358 575-580. (https://doi. org/10.1159/000126593)

58 Kiss JZ, Van Eekelen JAM, Reul HM, Westphal HM \& De Kloet ER. Glucocorticoid receptor in magnocellular neurosecretory cells. Endocrinology 1988122 444-449. (https://doi.org/10.1210/endo-1222-444)

59 Reul JMHM \& De Kloet ER. Two receptor systems for corticosterone in rat brain: microdistribution and differential occupation. Endocrinology 1985117 2505-2511. (https://doi.org/10.1210/endo117-6-2505)

60 Joëls M, Karst H, DeRijk R \& De Kloet ER. The coming out of the brain mineralocorticoid receptor. Trends in Neurosciences 200831 1-7. (https://doi.org/10.1016/j.tins.2007.10.005)

61 Conway-Campbell BL, George CL, Pooley JR, Knight DM, Norman MR, Hager GL \& Lightman SL. The HSP90 molecular chaperone cycle regulates cyclical transcriptional dynamics of the glucocorticoid receptor and its coregulatory molecules CBP/p300 during ultradian ligand treatment. Molecular Endocrinology 201125 944-954. (https://doi.org/10.1210/me.2010-0073)

62 Conway-Campbell BL, Pooley JR, Hager GL \& Lightman SL. Molecular dynamics of ultradian glucocorticoid receptor action. Molecular and Cellular Endocrinology 2012348 383-393. (https://doi. org/10.1016/j.mce.2011.08.014)

63 Conway-Campbell BL, McKenna MA, Wiles CC, Atkinson HC, De Kloet ER \& Lightman SL. Proteasome-dependent down-regulation of activated nuclear hippocampal glucocorticoid receptors determines dynamic responses to corticosterone. Endocrinology 2007148 5470-5477. (https://doi.org/10.1210/en.2007-0585)

64 Chao HM, Ma LY, McEwen BS \& Sakai RR. Regulation of glucocorticoid receptor and mineralocorticoid receptor messenger ribonucleic acids by selective agonists in the rat hippocampus. Endocrinology 1998139 1810-1814. (https://doi.org/10.1210/ endo.139.4.5896)

65 Dickens M, Romero LM, Cyr NE, Dunn IC \& Meddle SL. Chronic stress alters glucocorticoid receptor and mineralocorticoid receptor mRNA expression in the European starling (Sturnus vulgaris) brain. Journal of Neuroendocrinology 200921 832-840. (https://doi. org/10.1111/j.1365-2826.2009.01908.x)

66 Kalman BA \& Spencer RL. Rapid corticosteroid-dependent regulation of mineralocorticoid receptor protein expression in rat brain.
Endocrinology 2002143 4184-4195. (https://doi.org/10.1210/ en.2002-220375)

67 Meijer OC, Karssen AM \& De Kloet ER. Cell- and tissue-specific effects of corticosteroids in relation to glucocorticoid resistance: examples from the brain. Journal of Endocrinology 2003178 13-18.. (https://doi.org/10.1677/joe.0.1780013)

68 Makino S, Smith MA \& Gold PW. Increased expression of corticotropin-releasing hormone and vasopressin messenger ribonucleic acid (mrna) in the hypothalamic paraventricular nucleus during repeated stress: association with reduction in glucocorticoid receptor mrna levels. Endocrinology 1995136 3299-3309. (https:// doi.org/10.1210/endo.136.8.7628364)

69 Trapp T, Rupprecht R, Castren M, Reul JMHM \& Holsboer F. Heterodimerization between mineralocorticoid and glucocorticoid receptor: a new principle of glucocorticoid action in the CNS. Neuron 199413 1457-1462. (https://doi.org/10.1016/08966273(94)90431-6)

70 Caudal D, Jay TM \& Godsil BP. Behavioral stress induces regionallydistinct shifts of brain mineralocorticoid and glucocorticoid receptor levels. Frontiers in Behavioral Neuroscience 2014819.

71 Fitzsimons CP, Herbert J, Schouten M, Meijer OC, Lucassen PJ \& Lightman S. Circadian and ultradian glucocorticoid rhythmicity: implications for the effects of glucocorticoids on neural stem cells and adult hippocampal neurogenesis. Frontiers in Neuroendocrinology 201641 44-58. (https://doi.org/10.1016/j.yfrne.2016.05.001)

72 Conway-Campbell BL, Sarabdjitsingh RA, McKenna MA, Pooley JR, Kershaw YM, Meijer OC, De Kloet ER \& Lightman SL. Glucocorticoid ultradian rhythmicity directs cyclical gene pulsing of the clock gene period 1 in rat hippocampus. Journal of Neuroendocrinology 201022 1093-1100. (https://doi.org/10.1111/j.1365-2826.2010.02051.x)

73 Stavreva DA, Wiench M, John S, Conway-Campbell BL, McKenna MA, Pooley JR, Johnson TA, Voss TC, Lightman SL \& Hager GL. Ultradian hormone stimulation induces glucocorticoid receptor-mediated pulses of gene transcription. Nature Cell Biology 200911 1093-1102. (https://doi.org/10.1038/ncb1922)

74 George CL, Birnie MT, Flynn BP, Kershaw YM, Lightman SL \& Conway-Campbell BL. Ultradian glucocorticoid exposure directs gene-dependent and tissue-specific mRNA expression patterns in vivo. Molecular and Cellular Endocrinology 2017439 46-53. (https:// doi.org/10.1016/j.mce.2016.10.019)

75 McMaster A, Jangani M, Sommer P, Han N, Brass A, Beesley S, Lu W, Berry A, Loudon A, Donn R et al. Ultradian cortisol pulsatility encodes a distinct, biologically important signal. PLOS ONE 20116 e15766. (https://doi.org/10.1371/journal.pone.0015766)

76 Karst H, Berger S, Turiault M, Tronche F, Schutz G \& Joels M. Mineralocorticoid receptors are indispensable for nongenomic modulation of hippocampal glutamate transmission by corticosterone. PNAS 2005102 19204-19207. (https://doi. org/10.1073/pnas.0507572102)

77 Karst H, Berger S, Erdmann G, Schutz G \& Joels M. Metaplasticity of amygdalar responses to the stress hormone corticosterone. PNAS 2010107 14449-14454. (https://doi.org/10.1073/pnas.0914381107)

78 Sarabdjitsingh RA, Jezequel J, Pasricha N, Mikasova L, Kerkhofs A, Karst H, Groc L \& Joëls M. Ultradian corticosterone pulses balance glutamatergic transmission and synaptic plasticity. PNAS 2014111 14265-14270. (https://doi.org/10.1073/pnas.1411216111)

79 Sarabdjitsingh RA, Pasricha N, Smeets JAS, Kerkhofs A, Mikasova L, Karst H, Groc L \& Joëls M. Hippocampal fast glutamatergic transmission is transiently regulated by corticosterone pulsatility. PLoS ONE 201611 e0145858. (https://doi.org/10.1371/journal. pone.0145858)

80 Roozendaal B, Hernandez A, Cabrera SM, Hagewoud R, Malvaez M, Stefanko DP, Haettig J \& Wood MA. Membrane-associated glucocorticoid activity Is necessary for modulation of long-term memory via chromatin modification. Journal of Neuroscience 201030 5037-5046. (https://doi.org/10.1523/JNEUROSCI.5717-09.2010) 
81 Gutierrez-Mecinas M, Trollope AF, Collins A, Morfett H, Hesketh SA, Kersante F \& Reul JMHM. Long-lasting behavioral responses to stress involve a direct interaction of glucocorticoid receptors with ERK1/2MSK1-Elk-1 signaling. PNAS 2011108 13806-13811. (https://doi. org/10.1073/pnas.1104383108)

82 Haller J, Halasz J, Mikics É, Kruk MR \& Makara GB. Ultradian corticosterone rhythm and the propensity to behave aggressively in male rats. Journal of Neuroendocrinology 200012 937-940. (https:// doi.org/10.1046/j.1365-2826.2000.00568.x)

83 Sarabdjitsingh RA, Conway-Campbell BL, Leggett JD, Waite EJ, Meijer OC, De Kloet ER \& Lightman SL. Stress responsiveness varies over the ultradian glucocorticoid cycle in a brain-regionspecific manner. Endocrinology 2010151 5369-5379. (https://doi. org/10.1210/en.2010-0832)

84 Sarabdjitsingh RA, Spiga F, Oitzl MS, Kershaw Y, Meijer OC, Lightman SL \& Kloet ER de. Recovery from disrupted ultradian glucocorticoid rhythmicity reveals a dissociation between hormonal and behavioural stress responsiveness. Journal of Neuroendocrinology 201022 862-871. (https://doi.org/10.1111/j.13652826.2010.02004.x)

85 Scheff JD, Calvano SE, Lowry SF \& Androulakis IP. Transcriptional implications of ultradian glucocorticoid secretion in homeostasis and in the acute stress response. Physiological Genomics 201244 121-129. (https://doi.org/10.1152/physiolgenomics.00128.2011)

86 Gibbs J, Ince L, Matthews L, Mei J, Bell T, Yang N, Saer B, Begley N, Poolman T, Pariollaud M et al. An epithelial circadian clock controls pulmonary inflammation and glucocorticoid action. Nature Medicine 201420 919-926. (https://doi.org/10.1038/nm.3599)

87 Kondratova AA \& Kondratov R V. The circadian clock and pathology of the ageing brain. Nature Reviews Neuroscience 201213 325-335. (https://doi.org/10.1038/nrn3208)

88 Jeanneteau F \& Chao M V. Are BDNF and glucocorticoid activities calibrated? Neuroscience 2013239 173-195. (https://doi. org/10.1016/j.neuroscience.2012.09.017)

89 Young EA, Haskett RF, Murphy-Weinberg V, Watson SJ \& Akil H. Loss of glucocorticoid fast feedback in depression. Archives of General Psychiatry 199148 693-699. (https://doi.org/10.1001/ archpsyc.1991.01810320017003)

90 Miller GE, Cohen S \& Ritchey AK. Chronic psychological stress and the regulation of pro-inflammatory cytokines: a glucocorticoidresistance model. Health Psychology 200221 531-541. (https://doi. org/10.1037/0278-6133.21.6.531)

91 Brooke SM, de Haas-Johnson AM, Kaplan JR, Manuck SB \& Sapolsky RM. Dexamethasone resistance among nonhuman primates associated with a selective decrease of glucocorticoid receptors in the hippocampus and a history of social instability. Neuroendocrinology 199460 134-140. (https://doi.org/10.1159/000126743)

92 Bener D, Wohlman A, Itzik A, Yirmiya R, Ben-Hur T \& Weidenfeld J. Glucocorticoid resistance following herpes simplex-1 infection: role of hippocampal glucocorticoid receptors. Neuroendocrinology $2007 \mathbf{8 5}$ 207-215. (https://doi.org/10.1159/000102976)

93 Danan D, Matar MA, Kaplan Z, Zohar J \& Cohen H. Blunted basal corticosterone pulsatility predicts post-exposure susceptibility to PTSD phenotype in rats. Psychoneuroendocrinology 201887 35-42. (https://doi.org/10.1016/j.psyneuen.2017.09.023)

94 Symonds CS, McKie S, Elliott R, William Deakin JF \& Anderson IM. Detection of the acute effects of hydrocortisone in the hippocampus using pharmacological fMRI. European Neuropsychopharmacology 2012 22 867-874. (https://doi.org/10.1016/j.euroneuro.2012.03.008)

95 Henckens MJAG, van Wingen GA, Joels M \& Fernandez G. Timedependent corticosteroid modulation of prefrontal working memory processing. PNAS 2011108 5801-5806. (https://doi.org/10.1073/ pnas.1019128108)

96 Henckens MJAG, Pu Z, Hermans EJ, Van Wingen GA, Joëls M \& Fernández G. Dynamically changing effects of corticosteroids on human hippocampal and prefrontal processing. Human Brain Mapping 201233 2885-2897. (https://doi.org/10.1002/hbm.21409)

97 Fleischer J, Metz S, Düsenberg M, Grimm S, Golde S, Roepke S, Renneberg B, Wolf OT, Otte C \& Wingenfeld K. Neural correlates of glucocorticoids effects on autobiographical memory retrieval in healthy women. Behavioural Brain Research 2018 [Epub anead of print].

98 Veer IM, Oei NYL, Spinhoven P, Van Buchem MA, Elzinga BM \& Rombouts SA. Endogenous cortisol is associated with functional connectivity between the amygdala and medial prefrontal cortex. Psychoneuroendocrinology 201237 1039-1047. (https://doi. org/10.1016/j.psyneuen.2011.12.001)

99 Vaisvaser S, Lin T, Admon R, Podlipsky I, Greenman Y, Stern N, Fruchter E, Wald I, Pine DS, Tarrasch R et al. Neural traces of stress: cortisol related sustained enhancement of amygdala-hippocampal functional connectivity. Frontiers in Human Neuroscience 20137313. (https://doi.org/10.3389/fnhum.2013.00313)

100 Henckens MJ, van Wingen GA, Joëls M \& Fernández G. Corticosteroid induced decoupling of the amygdala in men. Cerebral Cortex 201222 2336-2345. (https://doi.org/10.1093/cercor/bhr313)

101 Vogel S, Klumpers F, Kroes MCW, Oplaat KT, Krugers HJ, Oitzl MS, Joëls M \& Fernández G. A stress-induced shift from trace to delay conditioning depends on the mineralocorticoid receptor. Biological Psychiatry 201578 830-839. (https://doi.org/10.1016/j. biopsych.2015.02.014)

102 Vogel S, Klumpers F, Krugers HJ, Fang Z, Oplaat KT, Oitzl MS, Joëls M \& Fernández G. Blocking the mineralocorticoid receptor in humans prevents the stress-induced enhancement of centromedial amygdala connectivity with the dorsal striatum. Neuropsychopharmacology 2015 40 947-956. (https://doi.org/10.1038/npp.2014.271)

103 Schwabe L, Tegenthoff M, Höffken O \& Wolf OT. Mineralocorticoid receptor blockade prevents stress-induced modulation of multiple memory systems in the human brain. Biological Psychiatry $2013 \mathbf{7 4}$ 801-808. (https://doi.org/10.1016/j.biopsych.2013.06.001)

104 Henckens MJ, van Wingen GA, Joëls M \& Fernández G. Timedependent effects of corticosteroids on human amygdala processing. Journal of Neuroscience 201030 12725-12732. (https://doi. org/10.1523/JNEUROSCI.3112-10.2010)

105 Henckens MJ, van Wingen GA, Joëls M \& Fernández G. Timedependent effects of cortisol on selective attention and emotional interference: a functional MRI study. Frontiers in Integrative Neuroscience 20126 66. (https://doi.org/10.3389/fnint.2012.00066)

106 de Quervain D, Schwabe L \& Roozendaal B. Stress, glucocorticoids and memory: implications for treating fear-related disorders. Nature Reviews Neuroscience 201718 7-19. (https://doi.org/10.1038/ nrn.2016.155)

107 McGaugh JL \& Roozendaal B. Role of adrenal stress hormones in forming lasting memories in the brain. Current Opinion in Neurobiology 200212 205-210.

108 Bourdeau I, Bard C, Noël B, Leclerc I, Cordeau MP, Bélair M, Lesage J, Lafontaine L \& Lacroix A. Loss of brain volume in endogenous Cushing's syndrome and its reversibility after correction of hypercortisolism. Journal of Clinical Endocrinology and Metabolism 200287 1949-1954. (https://doi.org/10.1210/jcem.87.5.8493)

109 Merke DP, Giedd JN, Keil MF, Mehlinger SL, Wiggs EA, Holzer S, Rawson E, Vaituzis AC, Stratakis CA \& Chrousos GP. Children experience cognitive decline despite reversal of brain atrophy one year after resolution of Cushing syndrome. Journal of Clinical Endocrinology and Metabolism 200590 2531-2536. (https://doi. org/10.1210/jc.2004-2488)

110 Maheu FS, Mazzone L, Merke DP, Keil MF, Stratakis CA, Pine DS \& Ernst M. Altered amygdala and hippocampus function in adolescents with hypercortisolemia: a functional magnetic resonance imaging study of Cushing syndrome. Development and Psychopathology 2008 20 1177-1189. (https://doi.org/10.1017/S0954579408000564) 
111 Turecki G \& Meaney MJ. Effects of the social environment and stress on glucocorticoid receptor gene methylation: a systematic review. Biological Psychiatry 201679 87-96. (https://doi.org/10.1016/j. biopsych.2014.11.022)

112 Merke DP, Fields JD, Keil MF, Vaituzis AC, Chrousos GP \& Giedd JN. Children with classic congenital adrenal hyperplasia have decreased amygdala volume: potential prenatal and postnatal hormonal effects. Journal of Clinical Endocrinology and Metabolism 200388 1760-1765. (https://doi.org/10.1210/jc.2002-021730)

113 Ernst M, Maheu FS, Schroth E, Hardin J, Golan LG, Cameron J, Allen R, Holzer S, Nelson E, Pine DS et al. Amygdala function in adolescents with congenital adrenal hyperplasia: a model for the study of early steroid abnormalities. Neuropsychologia $2007 \mathbf{4 5}$ 2104-2113. (https://doi.org/10.1016/j. neuropsychologia.2007.01.019)

114 Bergamaschi R, Livieri C, Uggetti C, Candeloro E, Egitto MG, Pichiecchio A, Cosi V \& Bastianello S. Brain white matter impairment in congenital adrenal hyperplasia. Archives of Neurology $2006 \mathbf{6 3}$ 413-416. (https://doi.org/10.1001/archneur.63.3.413)

115 Samia YM, Mahdi K, Baha Z, Saida JO, Tahar SM \& Habib SM. Congenital adrenal hyperplasia and brain magnetic resonance imaging abnormalities. Clinical Pediatric Endocrinology : Case Reports and Clinical Investigations 201019 109-113. https://doi.org/10.1297/ cpe.19.109)

116 Mnif MF, Kamoun M, Mnif F, Charfi N, Kallel N, Rekik N, Naceur BB, Fourati H, Daoud E, Mnif Z et al. Brain magnetic resonance imaging findings in adult patients with congenital adrenal hyperplasia: increased frequency of white matter impairment and temporal lobe structures dysgenesis. Indian Journal of Endocrinology and Metabolism 201317 121-127. (https://doi.org/10.4103/2230-8210.107833)

117 Plante E, Boliek C, Binkiewicz A \& Erly WK. Elevated androgen, brain development and language/learning disabilities in children with congenital adrenal hyperplasia. Developmental Medicine and Child Neurology 199638 423-437. (https://doi. org/10.1111/j.1469-8749.1996.tb15100.x)

118 Maheu FS, Merke DP, Schroth EA, Keil MF, Hardin J, Poeth K, Pine DS \& Ernst M. Steroid abnormalities and the developing brain: declarative memory for emotionally arousing and neutral material in children with congenital adrenal hyperplasia. Psychoneuroendocrinology 200833 238-245. (https://doi. org/10.1016/j.psyneuen.2007.11.006)

119 Lueken U, Leisse M, Mattes K, Naumann D, Wittling W \& Schweiger E. Altered tonic and phasic cortisol secretion following unilateral stroke. Psychoneuroendocrinology 200934 402-412. (https:// doi.org/10.1016/j.psyneuen.2008.10.002)

120 Martignoni E, Petraglia F, Costa A, Bono G, Genazzani AR $\&$ Nappi G. Dementia of the Alzheimer type and hypothalamus-pituitary-adrenocortical axis: changes in cerebrospinal fluid corticotropin releasing factor and plasma cortisol levels. Acta Neurologica Scandinavica 199081 452-456. (https://doi. org/10.1111/j.1600-0404.1990.tb00994.x)

121 Lei JK. [Change of serum ACTH and cortisol levels in Alzheimer disease and mild cognition impairment]. Zhonghua Yi Xue Za Zhi $2010902894-2896$.

122 Pariante CM \& Lightman SL. The HPA axis in major depression: classical theories and new developments. Trends in Neurosciences 2008 31 464-468. (https://doi.org/10.1016/j.tins.2008.06.006)

123 Cleare AJ. The HPA axis and the genesis of chronic fatigue syndrome. Trends in Endocrinology and Metabolism 200415 55-59. (https://doi. org/10.1016/j.tem.2003.12.002)

124 Calis M, Gökçe C, Ates F, Ülker S, Izgi HB, Demir H, Kirnap M, Sofuoglu S, Durak AC, Tutus A et al. Investigation of the hypothalamo-pituitary-adrenal axis (HPA) by $1 \mu \mathrm{g}$ ACTH test and metyrapone test in patients with primary fibromyalgia syndrome. Journal of Endocrinological Investigation 200427 42-46. (https://doi. org/10.1007/BF03350909)
125 Wingenfeld K, Heim C, Schmidt I, Wagner D, Meinlschmidt G \& Hellhammer DH. HPA axis reactivity and lymphocyte glucocorticoid sensitivity in fibromyalgia syndrome and chronic pelvic pain. Psychosomatic Medicine 200870 65-72. (https://doi.org/10.1097/ PSY.0b013e31815ff3ce)

126 Vargas I, Vgontzas AN, Abelson JL, Faghih RT, Morales KH \& Perlis ML. Altered ultradian cortisol rhythmicity as a potential neurobiologic substrate for chronic insomnia. Sleep Medicine Reviews 201841 234-243. (https://doi.org/10.1016/j.smrv.2018.03.003)

127 Andela CD, van Haalen FM, Ragnarsson O, Papakokkinou E, Johannsson G, Santos A, Webb SM, Biermasz NR, van der Wee NJ \& Pereira AM. Cushing's syndrome causes irreversible effects on the human brain: a systematic review of structural and functional magnetic resonance imaging studies. European Journal of Endocrinology 2015173 R1-R14. (https://doi.org/10.1530/EJE-14-1101)

128 Liu D, Ahmet A, Ward L, Krishnamoorthy P, Mandelcorn ED, Leigh R, Brown JP, Cohen A \& Kim H. A practical guide to the monitoring and management of the complications of systemic corticosteroid therapy. Allergy, Asthma, and Clinical immunology 2013 9 30. (https://doi.org/10.1186/1710-1492-9-30)

129 Russell GM \& Lightman SL. Can side effects of steroid treatments be minimized by the temporal aspects of delivery method? Expert Opinion on Drug Safety 201413 1501-1513. (https://doi.org/10.1517/ 14740338.2014.965141)

130 Løvås K, Loge JH \& Husebye ES. Subjective health status in Norwegian patients with Addison's disease. Clinical Endocrinology $200256581-588$.

131 Kluger N, Matikainen N, Sintonen H, Ranki A, Roine RP \& SchalinJäntti C. Impaired health-related quality of life in Addison's disease - Impact of replacement therapy, comorbidities and socio-economic factors. Clinical Endocrinology 201481 511-518. (https://doi. org/10.1111/cen.12484)

132 Meyer G, Hackemann A, Penna-Martinez M \& Badenhoop K. What affects the quality of life in autoimmune addison's disease? Hormone and Metabolic Research 201345 92-95. (https://doi. org/10.1055/s-0032-1331766)

133 Henry M, Wolf PSA, Ross IL \& Thomas KGF. Poor quality of life, depressed mood, and memory impairment may be mediated by sleep disruption in patients with Addison's disease. Physiology and Behavior 2015151 379-385. (https://doi.org/10.1016/j. physbeh.2015.08.011)

134 Wagenmakers MA, Netea-Maier RT, Prins JB, Dekkers T, den Heijer M $\&$ Hermus AR. Impaired quality of life in patients in long-term remission of Cushing's syndrome of both adrenal and pituitary origin: a remaining effect of long-standing hypercortisolism? European Journal of Endocrinology 2012167 687-695. (https://doi. org/10.1530/EJE-12-0308)

135 Løvås K \& Husebye ES. Continuous subcutaneous hydrocortisone infusion in Addison's disease. European Journal of Endocrinology 2007 157 109-112. (https://doi.org/10.1530/EJE-07-0052)

136 Björnsdottir S, Øksnes M, Isaksson M, Methlie P, Nilsen RM, Hustad S, Kämpe O, Hulting AL, Husebye ES, Løvås K et al. Circadian hormone profiles and insulin sensitivity in patients with Addison's disease: a comparison of continuous subcutaneous hydrocortisone infusion with conventional glucocorticoid replacement therapy. Clinical Endocrinology 201583 28-35. (https://doi.org/10.1530/EJE07-0052)

137 Bryan SM, Honour JW \& Hindmarsh PC. Management of altered hydrocortisone pharmacokinetics in a boy with congenital adrenal hyperplasia using a continuous subcutaneous hydrocortisone infusion. Journal of Clinical Endocrinology and Metabolism 200994 3477-3480. (https://doi.org/10.1210/jc.2009-0630)

138 Hindmarsh PC. The child with difficult to control Congenital Adrenal Hyperplasia: is there a place for continuous subcutaneous hydrocortisone therapy. Clinical Endocrinology 201481 15-18. (https://doi.org/10.1111/cen.12453) 
139 Sonnet E, Roudaut N \& Kerlan V. Results of the prolonged use of subcutaneous continuous infusion of hydrocortisone in a man with congenital adrenal hyperplasia. ISRN Endocrinology 20112011 219494. (https://doi.org/10.1530/EJE-07-0052)

140 Øksnes M, Björnsdottir S, Isaksson M, Methlie P, Carlsen S, Nilsen RM, Broman JE, Triebner K, Kämpe O, Hulting AL et al. Continuous subcutaneous hydrocortisone infusion versus oral hydrocortisone replacement for treatment of addison's disease: a randomized clinical trial. Journal of Clinical Endocrinology and Metabolism 201499 1665-1674. (https://doi.org/10.1210/jc.2013-4253)

141 Gagliardi L, Nenke MA, Thynne TRJ, von der Borch J, Rankin WA, Henley DE, Sorbello J, Inder WJ \& Torpy DJ. Continuous subcutaneous hydrocortisone infusion therapy in Addison's disease: a randomized, placebo-controlled clinical trial. Journal of Clinical Endocrinology and Metabolism 201499 4149-4157. (https://doi. org/10.1210/jc.2014-2433)

142 Nella AA, Mallappa A, Perritt AF, Gounden V, Kumar P, Sinaii N, Daley LA, Ling A, Liu CY, Soldin SJ et al. A phase 2 study of continuous subcutaneous hydrocortisone infusion in adults with congenital adrenal hyperplasia. Journal of Clinical Endocrinology and Metabolism 2016101 4690-4698. (https://doi.org/10.1210/jc.20161916)

143 Mallappa A, Nella AA, Sinaii N, Rao H, Gounden V, Perritt AF, Kumar P, Ling A, Liu CY, Soldin SJ et al. Long-term use of continuous subcutaneous hydrocortisone infusion therapy in patients with congenital adrenal hyperplasia. Clinical Endocrinology 201889 399-407. (https://doi.org/10.1111/cen.13813)

144 Kalafatakis K, Russell GM, Harmer CJ, Munafo MR, Marchant N, Wilson A, Brooks JCW, Thai NJ, Ferguson SG, Stevenson K et al. Effects of the pattern of glucocorticoid replacement on neural processing, emotional reactivity and well-being in healthy male individuals: study protocol for a randomised controlled trial. Trials 201617 44. (https://doi.org/10.1186/s13063-016-1159-x)

145 Kalafatakis K, Russell GM, Harmer CJ, Munafo MR, Marchant N, Wilson A, Brooks JC, Durant C, Thakrar J, Murphy P et al. Ultradian rhythmicity of plasma cortisol is necessary for normal emotional and cognitive responses in man. PNAS 2018115 E4091-E4100. (https:// doi.org/10.1073/pnas.1714239115)

Received 23 October 2018

Revised version received 14 November 2018

Accepted 23 November 2018 